\title{
Surgical Oncology: Sixth South Russian Rostov on Don October 2019
}

\author{
Horvath T* \\ Masaryk University, Faculty Of Medicine, Brno, Czech Republic, EU \\ *Corresponding author: Horvath T, Masaryk University, Faculty Of Medicine , Brno, Czech Republic, EU \\ To Cite This Article: Horvath T, Surgical Oncology: Sixth South Russian Rostov on Don October 2019. 2020 - 7(4). AJBSR.MS.ID.001162. \\ DOI: 10.34297/AJBSR.2020.07.001162.
}

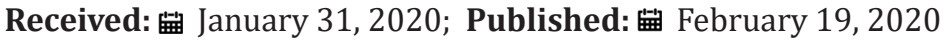

\begin{abstract}
Four dimensions of surgical oncology are characterized: premalignancy, surgical stage of the disease, locally advanced, and metastatic disease. The unity of knowledge and surgical action are underlined.
\end{abstract}

Keywords : Consilience; Oncology; Surgery

\section{Introduction}

Surgical oncologist is a peculiar element of the varied community of the vigorously engaging specialists in the struggle with the lethal disease. As the surgery is a teamwork par excellence, he knows, that a chain is as strong as its weakest link: in the spheres in which a pessimist is crying, which is a situation than I am willing not to take into account; where an optimist ingenuously bumps against a new challenge of disease, he ought as a realist to recall the success in a way "one for all and all for one" arranging matters in compliance with that and the chain becomes suddenly not to be broken. Components of surgical oncology [1,2] exist themselves alone-simultaneously, independently, with the same level of significance-without superiority or inferiority without merging or separating-creating a sole integral entirety characterized with a high difference and a profound equality of their parts. Although each of them represents specific issue, all of them belong to the specialty.

Surgical oncology would be ranked among the most comprehensive proficiencies supporting a view of legitimacy of the knowledge unity concept [3]. That is not a case of golden hands. It is much more attractive. It includes the delicate handling with tissue and organs as well the whole patient's human being. They are harmonized there the information of multilayered variety of oncogenes processes categorized by medical and other sciences, natural as well as human, with an important participation of technologies, with non-negligible roles of intuition and empiricismincluding manual labour. It is influenced by feedbacks proper to surgery and medicine, in the widest sense of the words, by statistics, economics, psychology, sociology and obviously also by politics.

Surgical oncologist saves tissue mindful of decrease of systemic inflammatory response to the operation. The observation of the development in the discipline welcomes every improvement in the patient care as a personal invitation. Introduce a multifaceted example of Non-Intubated Video-Assisted Thoracic Surgery (NIVATS): In this get enganged the knowledge of modern anatomy, physiology, pharmacology, and device technology with the courage of old masters. Through these physiological operative with respect to the function of the organs and tissue is presented. Despite of having had the roots in authentic tradition it is radically new. This provides impulses for further refinement in the surgery and anesthesy for mutual benefit of both.

Old habits die hard, getting warm every plenary sessions up to the boiling point: Neither surprise nor discourage for persuaded protagonists of the new method. On the contrary, an occasion to argue using appropriate toolls : Modesty, Decency, Truthfulness. They look into the controversy intubated/non-intubated as two different accents of one common issue: profit for patient. 


\section{Surgical Oncology is Created by Four Parts. Let's Define the Chapters in Single}

i. Surgery of premalignancy

ii. Treatment of "surgical stage" of oncological disease

iii. Surgery of locally advanced disease: Palliation, sanitation, devitalization, metaintervention

iv. Surgical treatment of metastatic disease $[4,5]$ :

a. surgery of solitary metastasis by means of the strategy identical with the second chapter.

b. surgery of general spreading of the disease, solving a local problem of the general extent by means of strategy like the saving treatments of the third chapter.

\section{To Remove the Focus before Cancer Emerges Sounds Call Word of the First Chapter}

I. The advanced premalignant changes are signaling a risk of cancer development in the tissue. Biopsy proof of the severe dysplasia leads to think about the presence of malignancy in the concerned focus with the whole appropriate surgical routine of work.

II. Another scenario is represented by mild or moderate dysplasia, at a given moment clinically insignificant. Their biological development in the subsequent phase is used to be difficult to guess, especially at the earlier detections. The context faced dilemma of overdiagnosis/overtreatment versus underdiagnosis/undertreatment:

a) The overdiagnosis represents clinically an irrelevant/ insignificant diagnosis, not requiring any treatment, because it would be superfluous-overtreatment, as express commonly used terms.

b) The underdiagnosis includes all varieties of diagnosis underestimation, usually in connection with an insufficient treatment-undertreatment with all consequences.

Decision making is not easy, but the surgical empiricism knows a rule of thumb: it is better to perform surgery unnecessarily than late. An example might be a diagnosis so "simple" as appendicitis, and a special example then a pulmonary coin lesion.

\section{Surgical Treatment of Carcinoma with a Curative Intent}

Preoperative counselling in the widest sense signifies offering and getting of all appropriate information, before an informed consent of the patient:

I. To communicate with the patient, having respect for all her/his personal (physical, psychical and spiritual), familiar, professional and social peculiarities.
II. To cultivate permanent relationships with specialists of imaging, medical and radiation oncology, cytology and histopathology, medicine, clinical psychology etc., to find an optimal, generally valid and acceptable solution [6].

That should precede the following steps:

a. Determination of one's own chirurgical strategy

b. Explanation of general organization of the surgical concept and special details referring to the patient

c. All that in accordance with up-to-date progress in the field of knowledge.

It doesn't remain as to say, that the strategy of the contemporary surgical oncology usually recommends considering radical surgery with enough safety border of healthy tissue by the smallest biologically acceptable anatomical resection in connection with regional lymphadenectomy in block-expressed by the term curative resection.

\section{Heterogenous Surgical Interventions there are Involved in the third Chapter, All with a Common Denominator}

Locally considerably advanced, radically predominantly insoluble disease. Procedures used in this category represent prospect for survival of incurable patient with amelioration of the quality of life. Exceptionally, they can become to a qualified effort for its radical solution, even if close to the extreme.

They are represented mainly by non-radical procedures:

A. Palliation-classical examples: the avoidance of inoperable obstacle of GIT passage by entero-enteroanastomosis, laser recanalisation of bronchus obstructed with tumors mass, or artificial reinforcement by stenting of ureter compressed by tumor.

B. Sanitation-the ablation of necrotic tumor mass even despite general spreading of disease, on account of massive secretion, of pungent odour, threatening to bleed to death.

C. Devitalization-trying to dissolve the extensive inoperable tumors by interruption of their vascular supply. Even if the argumentation of devitalization followers is from the point of view of general oncology in some respects incomplete, its supremely surgical ethos can't be neglected. As there is also the case of metaintervention, below mentioned. Surely under condition of nil nocere. While the indications of pal

liation and sanitation are obvious, devitalization can be always considered an enfant terrible.

D. Radical intervention in the chosen cases of locally extremely advanced disease with excluded distant metastases represents a relative novelty. It requires trans anatomical access 
often with utilization of (auto) transplantation and of artificial materials for replacement of infiltrated vascular structures. These procedures are issued from seasoned surgeons in wellcoordinated teams of top centers. They have their proponents and opponents. The indications are individual. In the essential argumentation compete technical realizability with biological authority. The internal strain of this type of conduct, could be perhaps expressed by the term metaintervention. The fundamental and global motive of this chapter too, is the life prolongation and improvement of its quality with an attitude, not at all just formal (!), and of great importance at any stage of disease: the help is possible. The most tragic expression of misunderstanding our profession, and under no circumstances unflagging work at full stretch of the surgical oncology, is as follows: The surgeon did not know what to do.

\section{Surgery of the Metastatic Disease is Very Specific Branch of Oncology}

A. More than at the synchronous metastases the treatment of distant solitary metachronous metastases evokes the access of the second chapter of surgical oncology. It should represent a complete resection with a curative intent. The others conclude about suitability of a simple excision of the lesion in the case of metachronous lesion, too. Valid data are lacking. A way downwards cannot be excused automatically. Each case must be judged individually in all given correlations.

B. Surgery of general spreading disease, e.g. a wedge excision of ten metastases of sarcoma to the lung, or the radiofrequency ablation of five metastatic focuses in the liver in terms of tumour mass reduction, for instance before perfusion chemotherapy, remains open. There are both their advocates and opponents.

C. Another category of the management of distant metastatic disease includes also palliative abdominocentesis for a tumour ascites, or talc poudrage of the interpleural space for a metastatic pleural effusion. The same procedures would be used in the part a/of the previous third chapter within the bounds of surgical palliation of the manifestation of locally advanced cancer of relevant organs.

\section{Conclusion}

No collective authority of a specialized indicating commission can remove from any individual surgeon the personal responsibility for the actual treatment sewed to the patient to measure-it is said today personalized. Definitive decision is sometimes done at the most dramatic moment of the surgical procedure. In that sense and in accordance with the above mentioned, a surgeon is not only a meek part of a deciding chain, but as an executive agent, he is autonomous. That does not weaken him; it strengthens him. The more he is well-educated and skilled, the more he is independent and free to make correct decisions. Surgery never means a defensive. The surgery, cheir ergein, means, apart from other things, the well informed, consequently reserved, nevertheless a strong fortitude to act.

\section{References}

1. Saclarides TJ, Millikan KW, Godellas CV (2003) Surgical Oncology: an algorithmic approach. Springer, New York, USA.

2. Chaudry MA, Winslet MC (2009) Surgical Oncology. Oxford University Press, UK.

3. Wilson EO (1998) Consilience: The Unity of Knowledge. Alfred A Knopf, New York, USA.

4. Duda M, Žaloudík J, Ryska M (2010) Surgical treatment of solid tumors in the Czech Republic. Perspectives in Surgery in Czech, Rozhl Chir 89(10): 588-593.

5. Žaloudík J (2010) Not Resting Surgeons or brief parametrical standard for surgical oncology. Perspectives in Surgery in Czech, Rozhl Chir 89(10): 583-587.

6. Horvath T (2019) Surgical Oncology. Medical Herald of the South Russia, Rostov State Medical University, Russia 10(3): 362-364. 